\title{
Automatic modeling using PENELOPE of two HPGe detectors used for measurement of environmental samples by $\gamma$-spectrometry from a few sets of experimental efficiencies
}

\author{
J. G. Guerra ${ }^{\mathrm{a}, *}$, J. G. Rubiano ${ }^{\mathrm{a}, \mathrm{b}}$, G. Winter ${ }^{\mathrm{c}}$, A. G. Guerra ${ }^{\mathrm{a}, \mathrm{b}}, \mathrm{H}$. Alonso ${ }^{\mathrm{a}, \mathrm{b}}$, M.A. Arnedo ${ }^{\mathrm{a}, \mathrm{b}}$, \\ A. Tejera ${ }^{\mathrm{a}, \mathrm{b}}$, F. Mosqueda ${ }^{\mathrm{d}}$, P. Martel $^{\mathrm{a}, \mathrm{b}}$, J.P. Bolivar ${ }^{\mathrm{d}}$ \\ a Departamento de Física, Universidad de Las Palmas de Gran Canaria, 3501 Las Palmas de Gran Canaria, Spain \\ ${ }^{\mathrm{b}}$ Instituto Universitario de Estudios Ambientales y Recursos naturales, Universidad de Las Palmas de Gran Canaria, 3501 Las Palmas de Gran Canaria, Spain \\ c Instituto Universitario de Sistemas Inteligentes y Aplicaciones Numéricas en la Ingeniería, Universidad de Las Palmas de Gran Canaria, 3501 Las Palmas de Gran \\ Canaria, Spain \\ d Departamento de Física Aplicada, Universidad de Huelva, 21071 Huelva, Spain
}

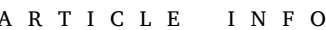

\section{Keywords:}

Gamma-ray spectrometry

Efficiency calibration

Reference materials

Monte Carlo simulation

\begin{abstract}
A $\quad$ B $\quad S \quad T \quad R \quad A \quad C \quad T$
The aim of this paper is to characterize two HPGe gamma-ray detectors used in two different laboratories for environmental radioactivity measurements, so as to perform efficiency calibrations by means of Monte Carlo Simulation. To achieve such an aim, methodologies developed in previous papers have been applied, based on the automatic optimization of the model of detector, so that the differences between computational and reference FEPEs are minimized. In this work, such reference FEPEs have been obtained experimentally from several measurements of the IAEA RGU-1 reference material for specific source-detector arrangements. The models of both detectors built through these methodologies have been validated by comparing with experimental results for several reference materials and different measurement geometries, showing deviations below $10 \%$ in most cases.
\end{abstract}

(C) 2017 Elsevier B.V. All rights reserved.

\section{Introduction}

When measuring samples by gamma-ray spectrometry, the Full Energy Peak Efficiencies (FEPEs) for the lines of interest must be determined. This is achieved by a process known as efficiency calibration of the detector, which can be performed by means of experimental procedures [1-3] or theoretical-mathematical methods [4-6], including the Monte Carlo simulation [7-9].

The efficiency calibration by direct Monte Carlo Simulation presents the clear advantage that it allows calculating FEPEs easily, rapidly and with enough precision without the need to perform any measurement of Certified Reference Materials (CRMs), with its consequent saving both economic and temporal [10-12]. However, in order to calculate reliable FEPEs, a computational detector model with a similar response to the real one must be used, which is obtained through a procedure known as detector characterization. Several works can be found in the literature about the characterization of gamma-ray detectors [13-15], including two papers previously published by the authors of the present work [16,17], in which automatic computational methodologies for the characterization of HPGe detectors have been developed.

In the first paper [16], a simple methodology of characterization is proposed, consisting in an implementation of a mono-objective optimization evolutionary algorithm, called Differential Evolution or DE [18], together with the Monte Carlo Simulation code PENELOPE [19], so that a computational model of the detector would be built automatically, with the only requirements of an accurate set of reference FEPEs for a specific sample-detector arrangement and material of the sample, but restricted to those beakers with a diameter lower than the crystal diameter of the detector. In the second [17], the methodology proposed in the first work was upgraded, eliminating such restriction by both improving the detector model and implementing a multi-objective Differential Evolution algorithm or DEMO [20] instead of its monoobjective precursor DE. In both cases, the methodologies proved to obtain successfully a detector model which generated FEPEs equivalent to the ones taken as reference, which were calculated, for a given

\footnotetext{
* Corresponding author.

E-mail address: jglezg2002@gmail.com (J.G. Guerra).
} 
detector, by Canberra's LabSOCS software [21], due to its flexibility to raise several cases for validating the methodologies proposed, avoiding at the same time imprecisions which could have appeared if reference experimental FEPEs had been used instead.

The present work aims to take a step forward, applying each methodology to a different HPGe detector owned by two different environmental laboratories, taking as reference the experimental FEPEs determined in such detectors, for a given reference material, IAEA RGU-1 [22] and a few source-detector arrangements, validating posteriorly the models built through these methodologies by comparing the calculated FEPEs with experimental results for different measurement geometries and reference materials. Finally, it is important to remark that this work does not aim to find the real characteristics of the detectors, but to get computational models which behave as similar as possible to the real detectors, even though the model characteristics might differ significantly from those of the real detector.

\section{Material and methods}

\subsection{Gamma ray detection systems, software and codes}

In this work, two Canberra HPGe detectors from two different laboratories of environmental radioactivity have been used. The first one (DET1), which belongs to the GIRMA group at the Department of Physics of the University of Las Palmas de Gran Canaria, is a model GX3518 with $38 \%$ of relative efficiency and nominal FWHM of $0.875 \mathrm{keV}$ at $122 \mathrm{keV}$ and $1.8 \mathrm{keV}$ at $1.33 \mathrm{MeV}$. The second one (DET2), owned by the FRyMA group at the Department of Applied Physics of the University of Huelva, is a GX3519 with $35 \%$ of relative efficiency and nominal FWHM of 0.95 $\mathrm{keV}$ at $122 \mathrm{keV}$ and $1.9 \mathrm{keV}$ at $1.33 \mathrm{MeV}$. Both detectors are situated into shields with $15 \mathrm{~cm}$ thick iron walls, located in a room with concrete walls and ceiling, and work together with multichannel analyzers and the Genie 2000 software package [23].

The Monte Carlo simulations for obtaining the computational FEPEs have been performed by the PENELOPE 2011 code [19]. Due to the cylindrical geometry of the detectors and samples, the pencyl.f subroutine, included in the PENELOPE distribution package for simulations for cylindrical geometry, has been used for controlling the entire simulation. The compilation of PENELOPE with pencyl.f as the main subroutine creates an executable, pencyl.exe, which requires an input file with the information needed for performing the simulations, it is to say, the geometry and materials of the detector and the definition of its active regions, geometry and materials of the sample and the beaker in which it is placed, type of radiation emitted by the source to be simulated $(\gamma$ or $\beta$ ) with its energies, duration of the simulation, etc.

As it will be explained below, the optimizations of both computational detector models are performed by the DE and DEMO algorithms $[18,20]$, programmed in scripts in Matlab@, together with the command lines to write, in PENELOPE input files, the definition of the geometric characteristics of the detector model (which represent a candidate solution in the optimization process) as well as the command lines for reading the PENELOPE output files with the information required to calculate the FEPEs for the desired energies.

\subsection{Reference materials and beakers}

For obtaining the experimental FEPEs used as reference during the optimization process of both computational detector models, the reference material IAEA RGU-1 has been chosen, whereas for the validation of such models, the RGU-1, RGTh-1, RGK-1, 447, 448, 434 and 326 from the IAEA and the DH-1a from the CANMET, have been used. IAEA RGU-1, RGTh-1 and RGK-1 are reference materials meant for the experimental calibration of gamma-ray spectrometers for Potassium, Uranium and Thorium [22]. IAEA 447 [24-26], IAEA 448 [26-28], IAEA $434[26,29,30]$ and IAEA $326[26,31]$ are environmental samples (moss-soil, contaminated soil from an oil field, Phosphogypsum and soil sample respectively) with certified activities for several radionuclides of interest for environmental radioactivity laboratories. With regard to the CANMET DH-1a [32,33] is an ore with a considerable concentration of both uranium and thorium $(0.2629 \% \mathrm{U}$ and $0.091 \% \mathrm{Th})$.

Fig. 1 shows the two types of beakers used in this work. Beakers type 1 are conventional beakers which are placed over the detector window, whilst beakers type 2 are Marinelli beakers which are placed wrapping the detector. In this work five different beakers have been used, three of them, beaker $1(\mathrm{D} 1=56 \mathrm{~mm}, \mathrm{D} 2=47.9 \mathrm{~mm}, \mathrm{H}=72.9 \mathrm{~mm}$ and $\mathrm{e}=$ $0.7 \mathrm{~mm}$ ), beaker $3(\mathrm{D} 1=38.5 \mathrm{~mm}, \mathrm{D} 2=35.6 \mathrm{~mm}, \mathrm{H}=62.9 \mathrm{~mm}$ and $\mathrm{e}=0.7 \mathrm{~mm})$ and beaker $5(\mathrm{D} 1=\mathrm{D} 2=52.2 \mathrm{~mm}, \mathrm{H}=21.4 \mathrm{~mm}$ and $\mathrm{e}$ $=0.3 \mathrm{~mm})$ are beakers type 1 , and two, beaker $2(\mathrm{D} 1=115.8 \mathrm{~mm}, \mathrm{D} 2$ $=79.2 \mathrm{~mm}, \mathrm{H} 1=103.3 \mathrm{~mm}, \mathrm{H} 2=70.2$ and $\mathrm{e}=2 \mathrm{~mm}$ ) and beaker 4 (D1 = $124.2 \mathrm{~mm}, \mathrm{D} 2=86.4 \mathrm{~mm}, \mathrm{H} 1=116.2 \mathrm{~mm}, \mathrm{H} 2=77.0$ and $\mathrm{e}$ $=2.2 \mathrm{~mm}$ ) are type 2 . With regard to the materials, beakers 1 to 4 are polypropylene beakers whereas beaker 5 is made of aluminum.

\subsection{Models of detectors}

DET1 has been characterized using the methodology developed in G. Guerra et al. [17] and DET2 using the methodology developed in G. Guerra et al. [16]. Table 1 contains the values of the known geometric characteristics of both computational models, which has been considered constant during the optimization process, the definition of the variables of the optimization problem (unknown characteristics), as well as the minimum and maximum values considered for each variable during the optimization process.

In addition to the different dimensions of the Germanium crystals, the main difference between both computational models is the consideration of a simplified crystal mount cap in the DET1 model [17]. This is needed in order to calculate FEPEs with enough accuracy in cases in which the beaker diameter is significantly larger than the germanium crystal one, being especially important in the case of Marinelli beakers, in which an important part of their volume surrounds the detector. Given the fact that the DET2 computational model does not include the mount cap, calculations with such model will only be suitable for beakers situated over the window with a maximum diameter equal to the crystal diameter. The materials considered for both computational models are aluminum for the housings and for the mount cap in DET1, carbon composite for the windows and germanium for the crystals (both for the active region and the dead layer).

\subsection{Determination of experimental FEPEs}

As it was mentioned in Section 2.2, the experimental FEPEs used as reference during the optimization process of both computational models, have been obtained by analyzing the reference material IAEA RGU-1 [22] by gamma spectrometry with different geometries. This material has been chosen because of its several reliable gamma emissions throughout the region of interest (45-1800 keV) for environmental radioactivity measurements. Concretely, a set of 8 gamma lines with energies within such interval (46.5, 63.3, 143.8, 186.0, 295.2, 352.0, 1001.0 and $1764.5 \mathrm{keV}$ ) has been chosen, as the corresponding full energy peaks stand out sufficiently from the Compton Continuum and are relatively free of interferences with other peaks in the spectra (which together implies acceptable area uncertainties), as well as because of being free of coincidence summing effects. Additionally, the quite well approximate knowledge of its chemical composition allows calculating FEPEs by Monte Carlo simulation at low energies with an acceptable accuracy.

For DET1 characterization process, beakers 1 and 2 have been completely filled with RGU-1 placing the first centered over the DET1 window at $1 \mathrm{~mm}$ of distance, and the second, a Marinelli beaker, with its internal face centered directly over the window, so that the sample surrounds an important part of the detector. These two sample-detector arrangements will be named $\mathrm{RA}_{1}$ and $\mathrm{RA}_{2}$ respectively throughout the 

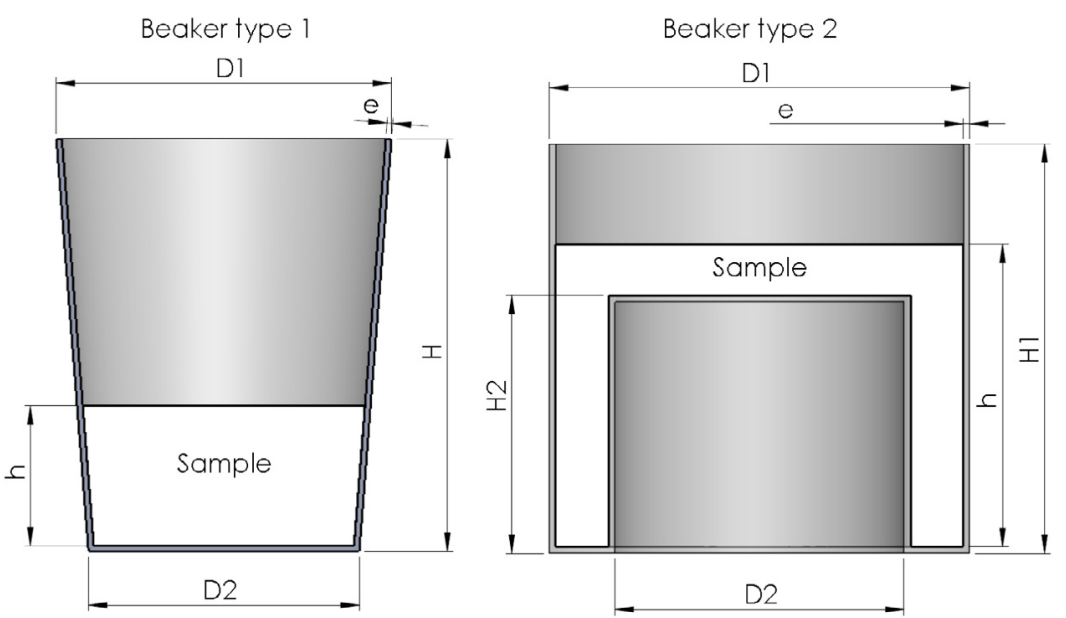

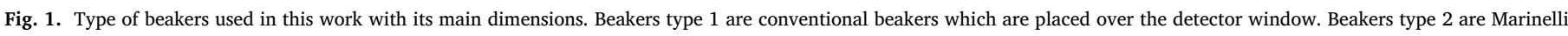
beakers which are placed wrapping the detector.

Table 1

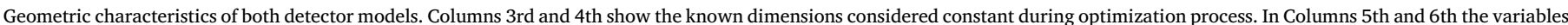

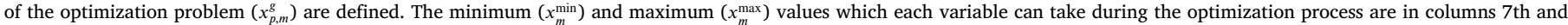
8th. Best solutions obtained are shown in columns 9th and 10th. All values are given in $\mathrm{mm}$.

\begin{tabular}{|c|c|c|c|c|c|c|c|c|c|c|c|}
\hline \multirow[t]{2}{*}{ Charac. } & \multirow[t]{2}{*}{ Denomination } & \multicolumn{2}{|c|}{ Dimensions } & \multicolumn{2}{|c|}{ Variable } & \multicolumn{2}{|l|}{$x_{m}^{\min }$} & \multicolumn{2}{|l|}{$x_{m}^{\max }$} & \multicolumn{2}{|c|}{ Solutions } \\
\hline & & DET1 & DET2 & DET1 & DET2 & DET1 & DET2 & DET1 & DET2 & DET1 & DET2 \\
\hline Hd & Housing diameter & \multicolumn{2}{|c|}{73.00} & - & - & - & - & - & - & - & - \\
\hline $\mathrm{Ht}$ & Housing thickness & \multicolumn{2}{|c|}{1.50} & - & - & - & - & - & - & - & - \\
\hline Wt & Window thickness & \multicolumn{2}{|c|}{0.60} & - & - & - & - & - & - & - & - \\
\hline $\mathrm{Cl}$ & Crystal length & 50.51 & 57.00 & - & - & - & - & - & - & - & - \\
\hline $\mathrm{Cd}$ & Crystal diameter & 59.52 & 58.50 & - & - & - & - & - & - & - & - \\
\hline Her & Higher curvature radius & - & - & \multicolumn{2}{|c|}{$x_{n+1}^{g}$} & \multicolumn{2}{|c|}{0.40} & \multicolumn{2}{|c|}{6.00} & 1.73 & 0.98 \\
\hline Dcw & Distance from crystal to window & - & - & & & \multicolumn{2}{|c|}{1.00} & \multicolumn{2}{|c|}{10.00} & 5.29 & 3.01 \\
\hline Dlt & Dead layer thickness & - & - & & & \multicolumn{2}{|c|}{0.10} & \multicolumn{2}{|c|}{5.00} & 0.92 & 2.43 \\
\hline Icd & Inactive core diameter & - & - & & & \multicolumn{2}{|c|}{1.00} & \multicolumn{2}{|c|}{47.50} & 17.52 & 2.12 \\
\hline Ich & Inactive core height & - & - & & & \multicolumn{2}{|c|}{15.00} & \multicolumn{2}{|c|}{50.00} & 24.53 & 20.25 \\
\hline Mct & Mount cap thickness & - & - & $x_{p, 6}^{g}$ & - & 0.50 & - & 4.00 & - & 2.90 & - \\
\hline
\end{tabular}

following lines for simplification purposes. With regard to DET2, beaker 3 has been filled up to $25 \mathrm{~mm}$ of RGU-1 and has been situated centered at $3.5 \mathrm{~mm}$ of distance $\left(\mathrm{RA}_{3}\right)$. In every case, once shut and sealed with aluminum tape, before performing each spectrum acquisition, the beakers have remained undisturbed for at least 4 weeks (approximately seven times the half-life of ${ }^{222} \mathrm{Rn}$ ) waiting for the radioactive equilibrium between ${ }^{226} \mathrm{Ra}$ and ${ }^{222} \mathrm{Rn}$.

Table 2 shows the experimental FEPEs $\left(\varepsilon_{\text {exp }}\right.$ ) used as reference during the characterization process of DET1 and DET2. Such experimental FEPEs and their uncertainties, as well as the ones used for the validation procedures in Section 3.2, have been determined by analyzing the spectra acquired for the corresponding sample-detector arrangements, and applying Eqs. (1) and (2), being $C$ the net counts observed in the relevant full energy peak (subtracting both Compton Continuum and laboratory background, performed by GENIE2000 [23]), [Ac] the activity concentration of the relevant radionuclide, $P_{\gamma}$ the probability of gamma emission for the corresponding radionuclide and gamma line, $t$ the acquisition time, $m$ the sample mass and CSCF the CoincidenceSumming Correction Factor, whereas, $u_{C}, u_{[A c]}, u_{P_{\gamma}}, u_{m}, u_{C S F C}$ are the corresponding uncertainties. In Eq. (2), the uncertainty related to the time has not been considered as it is negligible compared to the rest of elements within the radicand. The masses of the samples of RGU-1 in beakers 1, 2 and 3 are 221.1, 925.6 and $37.5 \mathrm{~g}$ respectively with an uncertainty of $0.1 \mathrm{~g}$, whereas the acquisition times have been 86749 , 68882 and 20644 s. Given the radioactive equilibrium among the different radionuclides of the ${ }^{238} \mathrm{U}$ decay series [22], for the calculations with Eqs. (1) and (2), [Ac] has been considered to be $4940 \pm 30$ for all energies, with the only exception of the line of $143.8 \mathrm{keV}$, for which $[A c]$ is $228 \pm 2$. The $P_{\gamma}$ and uncertainties considered have been obtained from the National Nuclear Data Center [34].

$$
\begin{aligned}
\varepsilon_{\text {exp }} & =\frac{C}{C S C F \cdot[A c] \cdot P_{\gamma} \cdot t \cdot m} \\
u_{\varepsilon_{\text {exp }}} & =\varepsilon_{\text {exp }} \sqrt{\left(\frac{u_{C}}{C}\right)^{2}+\left(\frac{u_{[A c]}}{[A c]}\right)^{2}+\left(\frac{u_{P_{\gamma}}}{P_{\gamma}}\right)^{2}+\left(\frac{u_{m}}{m}\right)^{2}+\left(\frac{u_{C S C F}}{C S C F}\right)^{2}} .
\end{aligned}
$$

The CSCF corresponding to the lines used as reference have been considered 1 (no coincidence summing effect) with negligible uncertainty. However, in the following sections, experimental FEPEs significantly affected by Coincidence Summing Effect are used. These are the corresponding to the gamma lines of 242.0,609.3, 1120.3 and $1238.1 \mathrm{keV}$ emitted by ${ }^{238} \mathrm{U}$ progeny and $338.3,583.2,727.3,860.0$ and $911.0 \mathrm{keV}$ emitted by ${ }^{232} \mathrm{Th}$ progeny. In such cases, the CSCF have been determined using the equations proposed by Xhixha et al. [35], except in the emission of $727.3 \mathrm{keV}$, for which the corresponding equation proposed by Tomarchio and Rizzo [36] has been used. In both works, the correction factors are calculated as function of the FEPEs and total efficiencies for the energies corresponding to the X-ray and $\gamma$-ray emissions which are likely to coincide with the main gamma emission, causing the coincidence-summing effect. In this work, for such calculations, the FEPEs and total efficiencies provided by the models of DET1 and DET2 in PENELOPE have been used. The uncertainties of such CSCF have been computed through uncertainty propagation.

\subsection{Optimization of the models}

The characterization methodologies applied in this work, consist in the optimization of a computational model for each detector, seeking 
Table 2

Experimental FEPEs used as reference during DET1 $\left(\mathrm{RA}_{1}\right.$ and $\left.\mathrm{RA} 2\right)$ and DET2 $\left(\mathrm{RA}_{3}\right)$ characterizations and their uncertainties.

\begin{tabular}{llllllll}
\hline Radionuclide & En $(\mathrm{keV})$ & $\varepsilon_{\exp _{R A_{1}}}$ & $u_{\varepsilon_{\exp _{R A_{1}}}}$ & $\varepsilon_{\exp _{R A_{2}}}$ & $u_{\varepsilon_{\exp _{R A_{2}}}}$ & $\varepsilon_{\exp _{R A_{3}}}$ & $u_{\varepsilon_{\exp _{R A_{3}}}}$ \\
\hline${ }^{210} \mathrm{~Pb}$ & 46.5 & 0.0325 & 0.0004 & 0.01576 & 0.00018 & 0.1006 & 0.0017 \\
${ }^{234} \mathrm{Th}$ & 63.3 & 0.0439 & 0.0010 & 0.0305 & 0.0007 & 0.120 & 0.003 \\
${ }^{235} \mathrm{U}+{ }^{223} \mathrm{Ra}$ & 143.8 & 0.0427 & 0.0012 & 0.0494 & 0.0010 & 0.113 & 0.006 \\
${ }^{236} \mathrm{Ra}+{ }^{235} \mathrm{U}$ & 186.0 & 0.0376 & 0.0004 & 0.0443 & 0.0004 & 0.0920 & 0.0013 \\
${ }^{214} \mathrm{~Pb}$ & 295.2 & 0.02496 & 0.00017 & 0.03129 & 0.00020 & 0.0587 & 0.0005 \\
${ }^{214} \mathrm{~Pb}$ & 352.0 & 0.02189 & 0.00014 & 0.02776 & 0.00018 & 0.0505 & 0.0004 \\
${ }^{234 \mathrm{~m}} \mathrm{~Pa}$ & 1001.0 & 0.00956 & 0.00026 & 0.01202 & 0.00020 & 0.0212 & 0.0012 \\
${ }^{214} \mathrm{Bi}$ & 1764.5 & 0.00599 & 0.00004 & 0.00790 & 0.00005 & 0.01296 & 0.00018 \\
\hline
\end{tabular}

for the geometric characteristics that minimize the differences between the experimental FEPEs considered as reference (Section 2.4), and the calculated FEPEs. The model of DET2 has been optimized using the DE algorithm [16,18], taking as reference the sample-detector arrangement $\mathrm{RA}_{3}$. Moreover, for the optimization of the model of DET1, the DEMO algorithm $[17,20]$ has been used, taking as reference the sampledetector arrangements $\mathrm{RA}_{1}$ and $\mathrm{RA}_{2}$.

Both optimization processes start with candidate solutions or individuals randomly generated at the beginning within the search domain $\left(x_{m}^{\min }-x_{m}^{\max }\right)$ (defined in Table 1 for each variable of the problem). These individuals are vectors $x_{p}^{g}=\left(x_{p, 1}^{g}, \ldots, x_{p, m}^{g}, \ldots, x_{p, n}^{g}\right)$, where each component, with index $m$, is a variable of the optimization problem $\left(x_{p, m}^{g}\right)$ (i.e. the unknown characteristics in Table $1, n=6$ in the case of DET1 and $n=5$ in the case of DET2), restricted within the mentioned search domain, whereas $g$ is the generation or iteration index and $p$ the individual or candidate index. The optimization is performed by creating new candidate solutions using the operators of mutation and crossover (both commonly used in evolutionary algorithms) and selecting the candidate solution with the best value for the optimization purpose, which is evaluated by the objective functions (only one in the case of the optimization of DET2 using DE, and two functions in the case of DET1 using DEMO). During the execution of both algorithms, the population size, it is to say the number of individuals, is maintained at a constant value NP. Further details can be found in previous papers $[16,17]$ where both computational methodologies applied in this work were developed and explained in detail.

The objective functions used for the selection phase are analytically expressed in Eq. (3), where $E_{i}$ is the energy of the full energy peak $i, R A_{j}$ the corresponding reference sample-detector arrangement, $\varepsilon_{\exp _{R A_{j}}}$ is the experimental FEPE taken as reference and $\varepsilon_{P E N_{R A_{j}}}$ the corresponding FEPE calculated for a specific individual $x_{p}^{g}$.

$f_{R A_{j}}\left(x_{p}^{g}\right)=\sum_{i=1}^{8}\left(\frac{\varepsilon_{P E N_{R A_{j}}}\left(x_{p}^{g}, E_{i}\right)-\varepsilon_{\exp _{R A_{j}}}\left(E_{i}\right)}{\varepsilon_{\exp _{R A_{j}}}\left(E_{i}\right)}\right)^{2} \begin{gathered}\text { for } j=1,2 \text { in DET } 1 \\ j=3 \text { in DET } 2 .\end{gathered}$

Regarding the parameters chosen for the execution of the optimization algorithms, a population size of ten times the number of variables has been chosen, as recommended in Storn and Price [18], it is to say, NP $=60$ in the case of the optimization of DET 1 by means of DEMO and NP $=50$ in the optimization of DET 2 by DE. In both optimization processes, the mutation (F) and crossover (CR) factors have been chosen 0.3 and 0.2 respectively. Both algorithms have been run during 100 generations (stopping criterion).

\subsection{Validation procedure}

The validation of the optimized models of DET1 and DET2 has been performed in two steps. First of all, the reference materials IAEA RGU-1, RGTh-1 and RGK-1 have been used to perform a comparison between experimental and computational FEPEs (results in Section 3.2.1.) for a wide variety of measurement geometries and for 19 gamma emissions within the energy range of interest (40-1800 keV), as can be seen in Tables 3 and 4 . The uncertainties of the experimental FEPEs, determined using Eq. (2), are within $0.6-4.7 \%$ in the case of DET1 and $0.7 \%-7.6 \%$ in DET2.
Secondly, the CRMs IAEA 447, 448, 434 and 326 and the CANMET DH-1a, have been measured for different geometries and bulk densities using the corresponding computational FEPEs, comparing subsequently the results of the analysis with the certified activities (Section 3.2.2.). For the measurements in DET1, the samples IAEA 447 and 448 were prepared in beaker 5 completely filled of such CRMs with a mass of $51 \mathrm{~g}$ and $47.3 \mathrm{~g}$ respectively. The samples of IAEA 434, 326 and CANMET DH-1a were prepared in beaker 3 with a height of 13.4, 23.0, $25.5 \mathrm{~mm}$ and a mass of 13.0, 30.0, 31.6 g respectively. With regard to the samples used for the measurements in DET2, the same samples IAEA 447 and 448 as in DET1 were measured, whereas the samples of IAEA 434, 326 and CANMET DH-1a were prepared in beaker 3 with a height of 17.5, 31.0, $26.9 \mathrm{~mm}$ and a mass of 20.5, 30.0, $31.6 \mathrm{~g}$ respectively.

Again, every sample has been measured at least 1 month after its preparation. However, in the case of the samples of IAEA 448 and CANMET DH-1a, due to their high concentrations of ${ }^{226} \mathrm{Ra}$, a considerable escape of ${ }^{222} \mathrm{Rn}$ has been noticed, reason why in such samples the concentration of ${ }^{226} \mathrm{Ra}$ has been obtained through its direct gamma line of $186 \mathrm{keV}$. In the case of the IAEA 448, this line can be used without performing any correction, as the ${ }^{235} \mathrm{U}$ content is negligible [27]. On the other hand, for DH-1a, a correction has been performed, discounting the theoretical counts due to the emission of ${ }^{235} \mathrm{U}$, based on its activity concentration determined through the line of $143.8 \mathrm{keV}$.

During both validation steps, the goodness of the optimized models has been evaluated using the relative bias or relative deviation (Eq. (4)), the zeta-score [37] (Eq. (5)) as well as the Precision Score (Eq. (6)), widely used by the IAEA in inter-comparisons and proficiency tests [3841], where $a \pm u_{a}$ is the measured or calculated value (the calculated FEPEs in Section 3.2.1 and the measured activities in Section 3.2.2) and $b \pm u_{b}$ the expected or reference value (the experimental FEPEs in Section 3.2.1 and the certified activities in Section 3.2.2).

$$
\begin{aligned}
R D(\%) & =\frac{a-b}{b} \cdot 100 \\
\zeta_{\text {score }} & =\frac{|a-b|}{\sqrt{u_{a}^{2}+u_{b}^{2}}} \\
P_{\text {score }} & =100 \cdot \sqrt{\left(\frac{u_{a}}{a}\right)^{2}+\left(\frac{u_{b}}{b}\right)^{2}} .
\end{aligned}
$$

The source of uncertainties in the calculated FEPEs are mainly the uncertainty of the experimental FEPEs used as reference during the characterization process, the statistic uncertainty of the PENELOPE calculations, the inaccuracy in the dimensions of the beakers and samples height considered for the calculations, as well as in the chemical composition and density of the materials considered. Given that there is no analytical expression which would allow propagating such sources of uncertainty, and that they cannot either be appropriately quantified, the uncertainties of the calculated FEPEs have been assigned so that the FEPEs calculated for the reference arrangements $\left(R A_{1}, R A_{2}\right.$ and $\mathrm{RA}_{3}$ ) and the corresponding experimental FEPEs are compatible within uncertainties, it is to say, an uncertainty of $5 \%$ for the calculations with the DET1 model and 6\% in DET2. 
Table 3

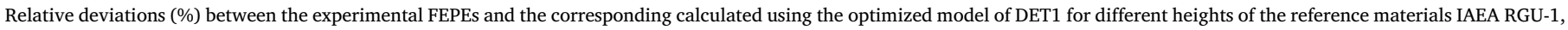
RGTh-1 and RGK-1 in the beaker 1 (B1), beaker 2 (B2), beaker 3 (B3) and beaker 4 (B4).

\begin{tabular}{|c|c|c|c|c|c|c|c|c|c|c|c|c|c|}
\hline \multirow[t]{3}{*}{ Material } & \multirow[t]{3}{*}{ Radionuclide } & \multirow[t]{3}{*}{ En (keV) } & \multicolumn{5}{|l|}{ B1 } & \multirow[t]{2}{*}{ B3 } & \multicolumn{2}{|l|}{ B2 } & \multicolumn{2}{|l|}{ B4 } & \multirow[t]{3}{*}{ Mean } \\
\hline & & & \multicolumn{9}{|c|}{ Height (mm) } & & \\
\hline & & & 22.3 & 32.7 & 42.6 & 52.1 & 72.2 & 62.2 & 68.2 & 101.3 & 74.8 & 114.0 & \\
\hline RGU-1 & ${ }^{210} \mathrm{~Pb}$ & 46.5 & -0.9 & 2.2 & -0.1 & 0.7 & 0.6 & -1.9 & 5.7 & 7.3 & 9.4 & 5.7 & 2.9 \\
\hline RGU-1 & ${ }^{234} \mathrm{Th}$ & 63.3 & -3.5 & -3.7 & -0.2 & -1.1 & -2.9 & -3.7 & 3.4 & -3.2 & 2.4 & 0.5 & -1.2 \\
\hline RGU-1 & ${ }^{235} \mathrm{U}+{ }^{223} \mathrm{Ra}$ & 143.8 & -2.2 & 2.0 & -3.8 & 2.6 & 0.6 & -2.9 & -6.1 & -4.3 & -8.1 & -0.9 & -2.3 \\
\hline RGU-1 & ${ }^{226} \mathrm{Ra}+{ }^{235} \mathrm{U}$ & 186.0 & -4.1 & -0.8 & -3.3 & -3.6 & -2.5 & -1.1 & -0.6 & -1.1 & -3.9 & 0.1 & -2.1 \\
\hline RGU-1 & ${ }^{214} \mathrm{~Pb}$ & 242.0 & 1.8 & 3.8 & 1.7 & 3.2 & 3.5 & 3.7 & 1.1 & 2.4 & -2.1 & 4.7 & 2.4 \\
\hline RGU-1 & ${ }^{214} \mathrm{~Pb}$ & 295.2 & 1.5 & 3.1 & 0.4 & 0.6 & 1.2 & 1.4 & -0.2 & 1.6 & -5.7 & 2.2 & 0.6 \\
\hline RGU-1 & ${ }^{214} \mathrm{~Pb}$ & 352.0 & -1.1 & 2.6 & -1.3 & -0.3 & -2.4 & 1.3 & -2.2 & -1.3 & -5.9 & -0.5 & -1.1 \\
\hline RGU-1 & ${ }^{214} \mathrm{Bi}$ & 609.3 & 4.7 & 7.8 & 5.7 & 8.8 & 8.3 & 9.2 & 4.2 & 4.3 & -0.5 & 4.9 & 5.7 \\
\hline RGU-1 & ${ }^{234 \mathrm{~m}} \mathrm{~Pa}$ & 1001.0 & -5.1 & -3.1 & 0.6 & -3.7 & -1.6 & 1.7 & -2.8 & 1.1 & -4.0 & -1.3 & -1.8 \\
\hline RGU-1 & ${ }^{214} \mathrm{Bi}$ & 1120.3 & 5.9 & 5.1 & 4.7 & 6.4 & 6.8 & 8.0 & 2.6 & 1.2 & 0.7 & 4.2 & 4.6 \\
\hline RGU-1 & ${ }^{214} \mathrm{Bi}$ & 1238.1 & 4.1 & 8.7 & 4.6 & 3.4 & 5.0 & 8.7 & 3.2 & 4.7 & -1.5 & 7.6 & 4.9 \\
\hline RGU-1 & ${ }^{214} \mathrm{Bi}$ & 1764.5 & 0.2 & 4.5 & -0.3 & 1.0 & 2.2 & -1.5 & 2.0 & -0.1 & -3.5 & -1.2 & 0.3 \\
\hline RGTh-1 & ${ }^{212} \mathrm{~Pb}$ & 238.6 & 1.2 & 1.4 & 2.2 & 0.5 & 0.7 & 2.4 & 0.8 & 1.0 & -3.4 & 0.8 & 0.8 \\
\hline RGTh-1 & ${ }^{228} \mathrm{Ac}$ & 338.3 & 4.7 & 4.2 & 5.1 & 2.3 & 4.7 & 4.6 & -0.3 & 3.5 & -3.5 & 4.8 & 3.0 \\
\hline RGTh-1 & ${ }^{208} \mathrm{Tl}$ & 583.2 & 3.8 & 4.9 & 5.5 & 6.4 & 5.1 & 6.8 & 2.8 & 4.8 & -2.1 & 2.8 & 4.1 \\
\hline RGTh-1 & ${ }^{212} \mathrm{Bi}+{ }^{228} \mathrm{Ac}$ & 727.3 & 2.2 & 3.7 & 4.8 & 4.8 & 2.4 & 1.9 & 0.0 & 1.3 & -2.4 & 2.9 & 2.2 \\
\hline RGTh-1 & ${ }^{208} \mathrm{Tl}$ & 860.0 & 2.0 & 0.3 & 1.0 & 2.0 & 1.6 & 1.2 & 0.8 & 1.2 & -3.6 & -1.6 & 0.5 \\
\hline RGTh-1 & ${ }^{228} \mathrm{Ac}$ & 911.0 & 0.8 & 0.1 & 2.3 & -0.3 & 0.6 & 2.6 & -2.0 & -1.8 & -5.9 & 0.1 & -0.4 \\
\hline \multirow[t]{2}{*}{ RGK-1 } & ${ }^{40} \mathrm{~K}$ & 1460.8 & 0.5 & -1.9 & -4.1 & 1.8 & -0.5 & -0.7 & -0.3 & 0.7 & -1.3 & 2.0 & -0.4 \\
\hline & & Mean & 0.9 & 2.4 & 1.3 & 1.9 & 1.8 & 2.2 & 0.6 & 1.2 & -2.4 & 2.0 & \\
\hline
\end{tabular}

Table 4

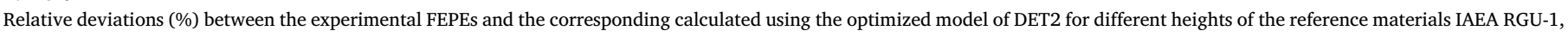
RGTh-1 and RGK-1 in the beaker 3.

\begin{tabular}{|c|c|c|c|c|c|c|c|c|c|c|c|c|c|}
\hline \multirow[t]{2}{*}{ Material } & \multirow[t]{2}{*}{ Radionuclide } & \multirow[t]{2}{*}{ En (keV) } & \multicolumn{10}{|c|}{ Height (mm) } & \multirow[t]{2}{*}{ Mean } \\
\hline & & & 5 & 10 & 15 & 20 & 25 & 30 & 35 & 40 & 45 & 50 & \\
\hline RGU-1 & ${ }^{210} \mathrm{~Pb}$ & 46.5 & 7.1 & 8.8 & 9.6 & 7.4 & 1.6 & 4.0 & 3.0 & 1.2 & 3.2 & 2.5 & 4.8 \\
\hline RGU-1 & ${ }^{234} \mathrm{Th}$ & 63.3 & -0.8 & 3.6 & 2.0 & 1.8 & -0.3 & -0.9 & -6.2 & -7.6 & -3.0 & -3.3 & -1.5 \\
\hline RGU-1 & ${ }^{235} \mathrm{U}+{ }^{223} \mathrm{Ra}$ & 143.8 & -2.3 & -8.4 & -4.3 & 4.6 & -6.7 & 3.5 & -6.4 & -3.5 & -2.4 & -4.3 & -3.0 \\
\hline RGU-1 & ${ }^{226} \mathrm{Ra}+{ }^{235} \mathrm{U}$ & 186.0 & 1.7 & 1.2 & -0.8 & 3.5 & -3.5 & -4.2 & -3.9 & -6.9 & -3.5 & -4.9 & -2.1 \\
\hline RGU-1 & ${ }^{214} \mathrm{~Pb}$ & 242.0 & 6.4 & 4.1 & 4.6 & 7.7 & 2.0 & 2.8 & -0.5 & -1.0 & 1.2 & -1.6 & 2.6 \\
\hline RGU-1 & ${ }^{214} \mathrm{~Pb}$ & 295.2 & 4.0 & 3.2 & 1.5 & 5.9 & 0.3 & 0.9 & -3.1 & -4.0 & 1.3 & -3.0 & 0.7 \\
\hline RGU-1 & ${ }^{214} \mathrm{~Pb}$ & 352.0 & 2.5 & 1.5 & -0.9 & 2.3 & 0.4 & -1.9 & -5.8 & -5.9 & -2.6 & -4.6 & -1.5 \\
\hline RGU-1 & ${ }^{214} \mathrm{Bi}$ & 609.3 & 6.2 & 9.1 & 5.5 & 7.9 & 4.3 & 4.1 & 1.7 & 2.3 & 4.5 & 3.1 & 4.9 \\
\hline RGU-1 & ${ }^{234 \mathrm{~m}} \mathrm{~Pa}$ & 1001.0 & -9.0 & 9.4 & -3.7 & 2.6 & -1.9 & 8.2 & -0.7 & -1.6 & 5.5 & 5.3 & 1.4 \\
\hline RGU-1 & ${ }^{214} \mathrm{Bi}$ & 1120.3 & 7.5 & 6.1 & 7.9 & 9.3 & 8.1 & 4.1 & 1.3 & 1.8 & 6.1 & 3.4 & 5.6 \\
\hline RGU-1 & ${ }^{214} \mathrm{Bi}$ & 1238.1 & 11.3 & 6.2 & 6.6 & 10.2 & 6.5 & 5.0 & -1.0 & -0.3 & 4.7 & 2.5 & 5.2 \\
\hline RGU-1 & ${ }^{214} \mathrm{Bi}$ & 1764.5 & 4.5 & 1.9 & 3.6 & 6.9 & -1.2 & -1.1 & -4.5 & -4.4 & 0.7 & -5.3 & 0.1 \\
\hline RGTh-1 & ${ }^{212} \mathrm{~Pb}$ & 238.6 & 6.5 & 2.8 & 8.8 & 1.7 & -2.1 & 0.8 & -0.1 & 2.5 & -1.2 & -2.4 & 1.7 \\
\hline RGTh-1 & ${ }^{228} \mathrm{Ac}$ & 338.3 & 10.9 & 8.1 & 10.0 & 5.3 & 1.2 & 2.1 & 4.2 & 5.6 & 3.7 & -0.4 & 5.1 \\
\hline RGTh-1 & ${ }^{208} \mathrm{Tl}$ & 583.2 & 5.2 & 2.9 & 8.7 & 4.7 & 2.3 & 2.2 & 2.1 & 5.4 & 3.0 & 4.7 & 4.1 \\
\hline RGTh-1 & ${ }^{212} \mathrm{Bi}+{ }^{228} \mathrm{Ac}$ & 727.3 & 10.8 & 3.7 & 10.0 & 2.5 & -2.0 & 1.2 & 0.6 & 3.9 & 1.3 & 3.6 & 3.6 \\
\hline RGTh-1 & ${ }^{208} \mathrm{Tl}$ & 860.0 & -0.7 & -3.0 & 2.8 & -2.5 & -4.3 & -4.9 & 1.4 & -1.7 & 2.4 & -1.4 & -1.2 \\
\hline RGTh-1 & ${ }^{228} \mathrm{Ac}$ & 911.0 & 10.5 & 5.5 & 7.6 & 1.3 & -1.1 & -2.9 & 2.3 & 2.2 & 1.2 & -3.5 & 2.3 \\
\hline \multirow[t]{2}{*}{ RGK-1 } & ${ }^{40} \mathrm{~K}$ & 1460.8 & - & 3.9 & - & 5.3 & - & 1.9 & - & -1.4 & - & -0.9 & 1.8 \\
\hline & & Mean & 4.6 & 3.7 & 4.4 & 4.7 & 0.2 & 1.3 & -0.9 & -0.7 & 1.5 & -0.6 & \\
\hline
\end{tabular}

\section{Results and discussion}

\subsection{Optimal solutions}

The solutions of the optimization process of both detectors models can be seen in the last two columns of Table 1. In the case of DET2, characterized using DE, the solution with minimum objective function ( $f_{R A_{3}} \approx 0.00483$ ) has been chosen. In the case of DET1, the DEMO algorithm reached several non-dominated solutions which would be theoretically equally acceptable. In this case, for selecting the definitive solution, the sum of both objective functions (the lower the value, the more approximate the behavior of the model to the reality) and the difference between them (the lower the value, the more the similarity of the model accuracy for both types of measurement geometries) have been chosen. Therefore, in this case the selected solution has been the one with the second best sum of both objective functions $\left(f_{R A_{1}} \approx\right.$ 0.00380 and $f_{R A_{2}} \approx 0.00382$ ) but with the lowest difference between both functions. The selection of this solution instead of the solution with best sum of functions ( $f_{R A_{1}}=0.00409$ and $\left.f_{R A_{2}}=0.00325\right)$ was due to the fact that, in this second option the sum is slightly lower than in the chosen option, whereas in the first option the difference is considerably lower than in the second option.

\subsection{Validation of the optimal models}

\subsubsection{Computational vs. experimental FEPEs}

The relative deviations (Eq. (4)) between the experimental and computational FEPEs can be seen in Tables 3 and 4. In such tables, the 19 emissions considered, the radionuclides which emit them, as well as the corresponding reference material are stated. As can be seen, most of cases present deviations below the uncertainties considered for the FEPEs calculations ( $85 \%$ of cases below the $5 \%$ for DET1 and $79 \%$ of cases below the $6 \%$ for DET2 model), whereas the average deviations for each geometry are below 3\% in every case in DET1 and 5\% in DET2, which is a good indicator of the goodness of the detector models built.

The zeta-score and $P_{\text {score }}$ values for all the sample-detector arrangements considered in this section can be seen in Fig. 2 for both detectors. In such a figure, it can be observed that all the zeta-score values are 

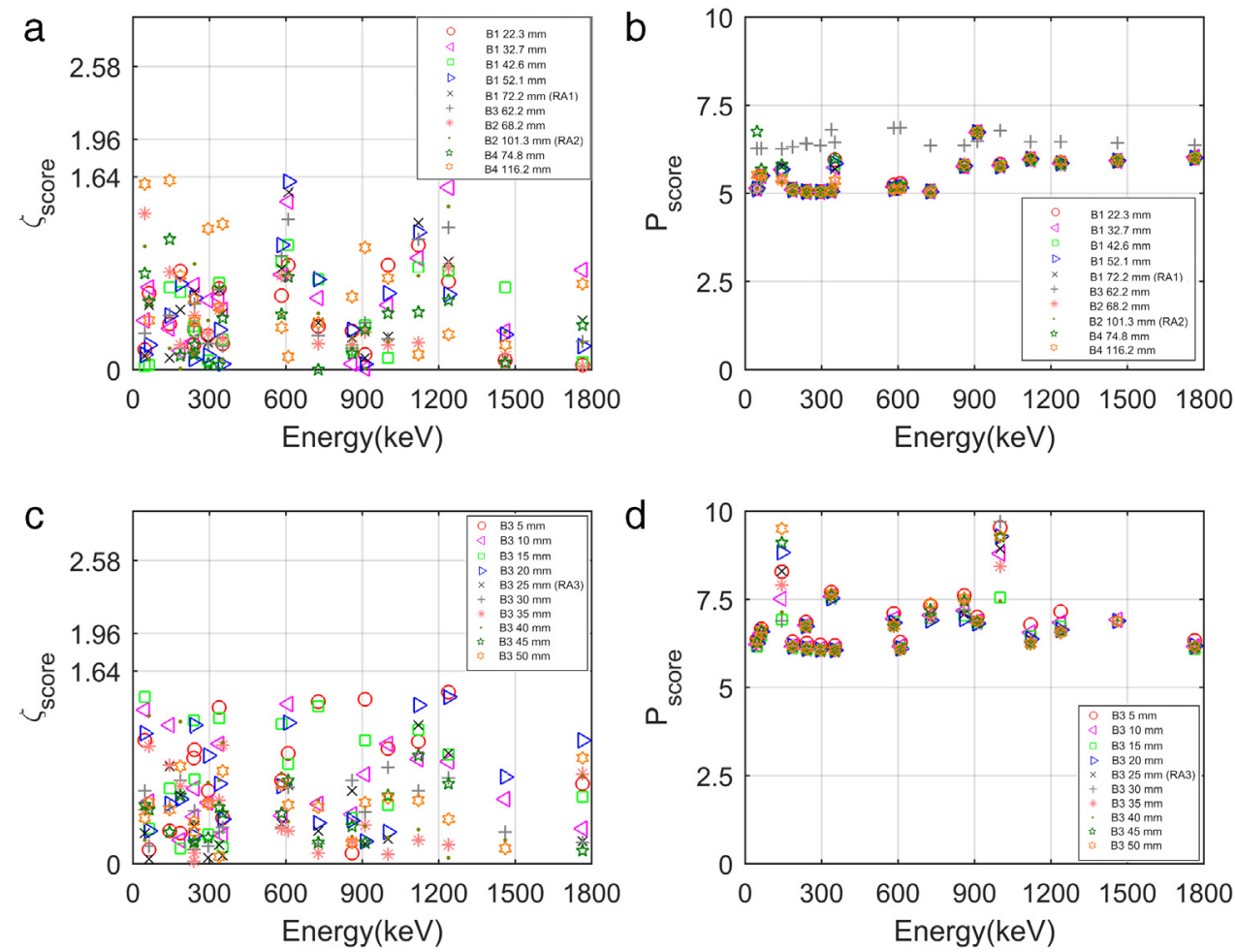

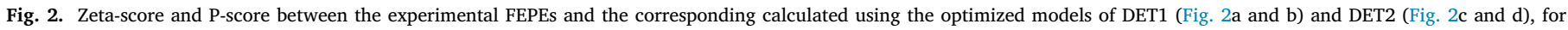
different heights of the reference materials IAEA RGU-1, RGTh-1 and RGK-1 in the beaker 1 (B1), beaker 2 (B2), beaker 3 (B3) and beaker 4 (B4).

below the limit of 1.64 (critical value for a normal distribution with a confidence level of $90 \%$ ), below which the results to be compared are not significantly different [42], confirming therefore the good agreement between the experimental FEPEs and the ones calculated for both computational models. With regard to the precisions scores, their values are within $5.1 \%-6.9 \%$ in the case of DET1 and within $6.0 \%-9.7 \%$ in case of DET2, but being most of them below the 7.5\%, which can be considered acceptable, as the limits of this test rarely are below $10 \%$ in the IAEA proficiency tests and inter-comparisons [38,39,41].

Therefore, the results of the zeta-score and $P_{\text {score }}$, confirm that the computational models built in this work, calculate FEPEs with an acceptable accuracy and precision, even for materials, energies and geometries different to the reference ones (stated in Section 2.4).

\subsubsection{Measurement of certified reference materials}

Tables 5 and 6 show the results of the CRMs measured in DET1 and DET 2 respectively using the corresponding computational FEPEs, as well as the reference values for the corresponding radionuclides, the relative deviation between them, the zeta-score and P-score values used for the comparison.

In both Tables 5 and 6 , most of cases show zeta-score values below the limit of 1.64 mentioned before, being all of them below 2.58 (critical value for a normal distribution with a confidence level of $99 \%$ ), used by the IAEA as limit in its proficiency tests and intercomparisons $[38,39,41]$. The precisions scores observed in such tables are also acceptable according to the limits set in the IAEA proficiency tests and inter-comparisons, commonly within 15\%-30\% for natural radionuclides in environmental samples, depending on the type of sample, level of activity, radionuclide, etc. [29,43-45].

\section{Conclusions}

Two HPGe gamma-ray detectors owned by two different research laboratories on environmental radioactivity have been characterized, using a different automatic characterization methodology for each one. Such methodologies consist of using evolutionary algorithms for searching the optimal detector model built in a Monte Carlo code, so that the calculated FEPEs are as similar as possible to the reference ones, determined in this work experimentally using the reference material IAEA RGU-1 for a few reference sample-detector arrangements. In this work the PENELOPE code has been used for the Monte Carlo simulations, however, other similar codes may be used, provided that such code permits performing an automatic optimization commanded by a main script, where the optimization algorithms are implemented.

For the validation of the optimal detector models obtained, calculated FEPEs have been compared to the corresponding experimental ones for a wide variety of geometries, susceptible to be used during the normal operation of such detectors, and for the three reference materials IAEA RGU-1, RGTh-1 and RGK-1, observing acceptable deviations, most of which below $10 \%$. In order to check the good agreement between the computational and experimental FEPEs, the zeta-score and P-score have been used, observing that in every case studied, the limits of $1.64 \%$ and $10 \%$ respectively have not been surpassed, which confirms that the models generate FEPEs with an acceptable accuracy and precision according to the requirements set by the IAEA in its proficiency tests and inter-comparisons.

Additionally, several samples of CRMs have been measured in both detectors, also for different sample geometries, calibrating in efficiency using the corresponding calculated FEPEs for the subsequent comparison between the results of the spectrometric analysis and the certified activities. Again, the z-score and P-score have been used, confirming the goodness of the detectors models.

To conclude, despite the relative simplicity and rapidity of the methodologies applied in this work, without the necessity of having the detectors inoperative for a long period nor using very refined techniques, and having started from a limited knowledge of the actual geometrical characteristics of the detectors, the two models of HPGe detectors obtained allow performing efficiency calibrations suitable for the measurement of environmental samples by gamma spectrometry. 
Table 5

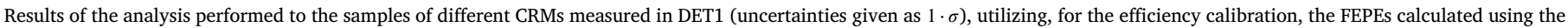
optimized model . Comparison of the measured values with the values certified by the IAEA and CANMET (Measurement dates provided in first column).

\begin{tabular}{|c|c|c|c|c|c|c|c|}
\hline CRM & Radionuclide & En $(\mathrm{keV})$ & Certified $[\mathrm{Ac}](\mathrm{Bq} / \mathrm{kg})^{\mathrm{a}}$ & Measured [Ac] (Bq/kg) & $\mathrm{RD}(\%)$ & Zeta-score & P-score \\
\hline \multirow{6}{*}{ IAEA 447(16th June 2017 ) } & ${ }^{210} \mathrm{~Pb}$ & 46.5 & $337 \pm 16$ & $341 \pm 18$ & 1.1 & 0.16 & 7.2 \\
\hline & ${ }^{137} \mathrm{Cs}$ & 661.7 & $357 \pm 8$ & $325 \pm 16$ & -8.8 & 1.70 & 5.6 \\
\hline & ${ }^{40} \mathrm{~K}$ & 1460.8 & $550 \pm 20$ & $472 \pm 27$ & -14.3 & 2.34 & 6.8 \\
\hline & ${ }^{228} \mathrm{Ac}$ & 911.0 & $37 \pm 2$ & $31.7 \pm 2.5$ & -14.5 & 1.65 & 9.7 \\
\hline & ${ }^{212} \mathrm{~Pb}$ & 238.6 & $37.0 \pm 1.5$ & $33.6 \pm 1.9$ & -9.2 & 1.41 & 7.0 \\
\hline & ${ }^{226} \mathrm{Ra}$ & $352.0\left({ }^{214} \mathrm{~Pb}\right)$ & $25 \pm 2$ & $23.4 \pm 1.6$ & -6.3 & 0.62 & 10.5 \\
\hline \multirow{3}{*}{ IAEA 448(13rd February 2017 ) } & ${ }^{226} \mathrm{Ra}$ & 186.0 & $18980 \pm 260$ & $17600 \pm 900$ & -7.6 & 1.51 & 5.4 \\
\hline & ${ }^{210} \mathrm{~Pb}$ & 46.5 & $8200 \pm 400$ & $7900 \pm 400$ & -4.0 & 0.61 & 6.8 \\
\hline & ${ }^{208} \mathrm{Tl}$ & 583.2 & $1010 \pm 40$ & $1040 \pm 60$ & 2.8 & 0.40 & 6.9 \\
\hline \multirow{4}{*}{ IAEA 434(5th May 2017 ) } & ${ }^{228} \mathrm{Ac}$ & 911.0 & $690 \pm 30$ & $660 \pm 50$ & -5.2 & 0.60 & 8.9 \\
\hline & ${ }^{210} \mathrm{~Pb}$ & 46.5 & $700 \pm 60$ & $650 \pm 40$ & -6.7 & 0.69 & 10.0 \\
\hline & ${ }^{226} \mathrm{Ra}$ & $352.0\left({ }^{214} \mathrm{~Pb}\right)$ & $780 \pm 60$ & $680 \pm 40$ & -12.4 & 1.36 & 9.5 \\
\hline & ${ }^{238} \mathrm{U}$ & $63.3\left({ }^{234} \mathrm{Th}\right)$ & $120 \pm 11$ & $113 \pm 14$ & -5.5 & 0.37 & 15.5 \\
\hline \multirow{4}{*}{ IAEA 326(6th May 2017 ) } & ${ }^{40} \mathrm{~K}$ & 1460.8 & $580 \pm 9$ & $510 \pm 30$ & -12.5 & 2.26 & 6.2 \\
\hline & ${ }^{210} \mathrm{~Pb}$ & 46.5 & $43 \pm 4$ & $48 \pm 6$ & 11.9 & 0.69 & 16 \\
\hline & ${ }^{226} \mathrm{Ra}$ & $352.0\left({ }^{214} \mathrm{~Pb}\right)$ & $32.6 \pm 1.6$ & $31 \pm 2$ & -5.7 & 0.71 & 8.3 \\
\hline & ${ }^{228} \mathrm{Ra}$ & $911\left({ }^{228} \mathrm{Ac}\right)$ & $39.6 \pm 1.8$ & $37 \pm 3$ & -6.1 & 0.63 & 10.2 \\
\hline \multirow{6}{*}{ CANMET DH-1a(9th May 2017 ) } & ${ }^{238} \mathrm{U}$ & $63.3\left({ }^{234} \mathrm{Th}\right)$ & $29.4 \pm 1.3$ & $29 \pm 5$ & -0.1 & 0.01 & 17.9 \\
\hline & ${ }^{210} \mathrm{~Pb}$ & 46.5 & $31100 \pm 900$ & $27800 \pm 1400$ & -10.4 & 1.91 & 5.9 \\
\hline & ${ }^{235} \mathrm{U}$ & 143.8 & $1498.0 \pm 2.0$ & $1520 \pm 80$ & 1.3 & 0.22 & 5.6 \\
\hline & ${ }^{238} \mathrm{U}$ & $63.3\left({ }^{234} \mathrm{Th}\right)$ & $32450 \pm 40$ & $30000 \pm 1700$ & -6.5 & 1.26 & 5.5 \\
\hline & ${ }^{226} \mathrm{Ra}$ & $186.0^{\mathrm{b}}$ & $31500 \pm 1100$ & $29000 \pm 3000$ & -8.0 & 0.78 & 11.0 \\
\hline & ${ }^{232} \mathrm{Th}$ & $911\left({ }^{228} \mathrm{Ac}\right)$ & $3680 \pm 120$ & $3720 \pm 200$ & 1.2 & 0.19 & 6.3 \\
\hline
\end{tabular}

a Certified activity concentrations for the corresponding radionuclides corrected for radioactive decay and equilibrium with their radioactive precursors using Bateman equations.

${ }^{b}$ Determined through the direct peak of $186 \mathrm{keV}$, with counts from both ${ }^{226} \mathrm{Ra}$ and ${ }^{235} \mathrm{U}$, discounting the theoretical counts due to the emission of ${ }^{235} \mathrm{U}$, based on the ${ }^{235} \mathrm{U}$ activity concentration determined through the line of $143.8 \mathrm{keV}$.

Table 6

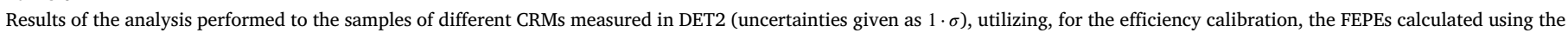
optimized model . Comparison of the measured values with the values certified by the IAEA and CANMET (Measurement dates provided in first column).

\begin{tabular}{|c|c|c|c|c|c|c|c|}
\hline CRM & Radionuclide & En $(\mathrm{keV})$ & Certified $[\mathrm{Ac}](\mathrm{Bq} / \mathrm{kg})^{\mathrm{a}}$ & Measured $[\mathrm{Ac}](\mathrm{Bq} / \mathrm{kg})$ & $\mathrm{RD}(\%)$ & Zeta-score & P-score \\
\hline \multirow{6}{*}{ IAEA 447(11th July 2017) } & ${ }^{210} \mathrm{~Pb}$ & 46.5 & $336 \pm 16$ & $376 \pm 24$ & 12.0 & 1.41 & 7.9 \\
\hline & ${ }^{137} \mathrm{Cs}$ & 661.7 & $356 \pm 8$ & $354 \pm 21$ & -0.5 & 0.08 & 6.5 \\
\hline & ${ }^{40} \mathrm{~K}$ & 1460.8 & $550 \pm 20$ & $540 \pm 30$ & -2.1 & 0.29 & 7.4 \\
\hline & ${ }^{228} \mathrm{Ac}$ & 911.0 & $37 \pm 2$ & $34.8 \pm 2.7$ & -6.0 & 0.66 & 9.5 \\
\hline & ${ }^{212} \mathrm{~Pb}$ & 238.6 & $37.0 \pm 1.5$ & $37.0 \pm 2.3$ & -0.1 & 0.02 & 7.5 \\
\hline & ${ }^{226} \mathrm{Ra}$ & $352.0\left({ }^{214} \mathrm{~Pb}\right)$ & $25 \pm 2$ & $20.7 \pm 1.6$ & -16.9 & 1.63 & 11.3 \\
\hline \multirow{4}{*}{ IAEA 448(7th July 2017) } & ${ }^{226} \mathrm{Ra}$ & 186.0 & $18980 \pm 260$ & $17700 \pm 1100$ & -6.8 & 1.15 & 6.3 \\
\hline & ${ }^{210} \mathrm{~Pb}$ & 46.5 & $8400 \pm 400$ & $8000 \pm 500$ & -4.4 & 0.61 & 7.5 \\
\hline & ${ }^{208} \mathrm{Tl}$ & 583.2 & $960 \pm 40$ & $960 \pm 60$ & -0.8 & 0.10 & 7.7 \\
\hline & ${ }^{228} \mathrm{Ac}$ & 911.0 & $660 \pm 30$ & $650 \pm 50$ & -1.8 & 0.2 & 9.1 \\
\hline \multirow{3}{*}{ IAEA 434(27th December 2016) } & ${ }^{210} \mathrm{~Pb}$ & 46.5 & $700 \pm 60$ & $660 \pm 40$ & -6.0 & 0.59 & 10.5 \\
\hline & ${ }^{226} \mathrm{Ra}$ & $352.0\left({ }^{214} \mathrm{~Pb}\right)$ & $780 \pm 60$ & $730 \pm 40$ & -6.3 & 0.64 & 10.0 \\
\hline & ${ }^{238} \mathrm{U}$ & $63.3\left({ }^{234} \mathrm{Th}\right)$ & $120 \pm 11$ & $120 \pm 16$ & -0.3 & 0.02 & 16.0 \\
\hline \multirow{5}{*}{ IAEA 326(3rd February 2015) } & ${ }^{40} \mathrm{~K}$ & 1460.8 & $580 \pm 9$ & $670 \pm 40$ & 15.1 & 2.00 & 6.6 \\
\hline & ${ }^{210} \mathrm{~Pb}$ & 46.5 & $43 \pm 4$ & $47 \pm 5$ & 9.4 & 0.62 & 14.2 \\
\hline & ${ }^{226} \mathrm{Ra}$ & $352.0\left({ }^{214} \mathrm{~Pb}\right)$ & $32.6 \pm 1.6$ & $35.6 \pm 2.4$ & 9.0 & 1.03 & 8.3 \\
\hline & ${ }^{228} \mathrm{Ra}$ & $911\left({ }^{228} \mathrm{Ac}\right)$ & $39.6 \pm 1.8$ & $42 \pm 3$ & 5.6 & 0.59 & 9.1 \\
\hline & ${ }^{238} \mathrm{U}$ & $63.3\left({ }^{234} \mathrm{Th}\right)$ & $29.4 \pm 1.3$ & $33 \pm 6$ & 11.0 & 0.55 & 17.9 \\
\hline \multirow{5}{*}{ CANMET DH-1a(20th March 2017) } & ${ }^{210} \mathrm{~Pb}$ & 46.5 & $31100 \pm 900$ & $27900 \pm 1700$ & -10.1 & 1.62 & 6.8 \\
\hline & ${ }^{235} \mathrm{U}$ & 143.8 & $1498.0 \pm 2.0$ & $1590 \pm 110$ & 6.2 & 0.82 & 7.1 \\
\hline & ${ }^{238} \mathrm{U}$ & $63.3\left({ }^{234} \mathrm{Th}\right)$ & $32450 \pm 40$ & $31600 \pm 2000$ & -2.6 & 0.42 & 6.4 \\
\hline & ${ }^{226} \mathrm{Ra}$ & $186.0^{\mathrm{b}}$ & $31500 \pm 1100$ & $33000 \pm 4000$ & 3.9 & 0.30 & 12.6 \\
\hline & ${ }^{232} \mathrm{Th}$ & $911\left({ }^{228} \mathrm{Ac}\right)$ & $3680 \pm 120$ & $3930 \pm 260$ & 6.8 & 0.88 & 7.3 \\
\hline
\end{tabular}

a Certified activity concentrations for the corresponding radionuclides corrected for radioactive decay and equilibrium with their radioactive precursors using Bateman equations.

${ }^{b}$ Determined through the direct peak of $186 \mathrm{keV}$ with counts from both ${ }^{226} \mathrm{Ra}$ and ${ }^{235} \mathrm{U}$, discounting the theoretical counts due to the emission of ${ }^{235} \mathrm{U}$, based on the ${ }^{235} \mathrm{U}$ activity concentration determined through the line of $143.8 \mathrm{keV}$.

\section{Acknowledgments}

This work has been partially financed by the Nuclear Safety Council of Spain (CSN) R \& D program 2009 through the research project "Estudio sobre la distribución de radioisótopos naturales y de radón en las Islas Canarias Orientales" and R \& D program 2012 through the research project "Estudio de las concentraciones de radón en viviendas, lugares de trabajo y materiales de construcción en las Islas Canarias Orientales".

This research has been partially supported by the project of the Ministry of MINECO (Ref.: CTM2015-68628-R).
J.G. Guerra acknowledges a PhD fellowship through the "Programa de personal investigador pre-doctoral en formación (Convocatoria 2015)" of the ULPGC.

\section{References}

[1] J.P. Pérez-Moreno, E.G. San Miguel, J.P. Bolívar, J.L. Aguado, Nucl. Instrum. Methods Phys. Res. A 491 (2002) 152.

[2] A.-R. Iurian, C. Cosma, Nucl. Instrum. Methods Phys. Res. A 763 (2014) 132.

[3] P. Tayyebi, F.A. Davani, M. Tabasi, H. Afarideh, Radiat. Phys. Chem. 133 (2017) 86.

[4] S.S. Nafee, M.I. Abbas, Nucl. Instrum. Methods Phys. Res. A 592 (2008) 80.

[5] P.C. Ortiz-Ramírez, Nucl. Instrum. Methods Phys. Res. A 793 (2015) 49. 
[6] M.S. Badawi, M.M. Gouda, S.S. Nafee, A.M. El-Khatib, E.A. El-Mallah, Nucl. Instrum. Methods Phys. Res. A 696 (2012) 164.

[7] L. Liye, M. Jizeng, D. Franck, L. de Carlan, Z. Binquan, Nucl. Instrum. Methods Phys. Res. A 564 (2006) 608.

[8] A. Tedjani, C. Mavon, A. Belafrites, D. Degrelle, D. Boumala, D. Rius, J.-E. Groetz, Nucl. Instrum. Methods Phys. Res. A 838 (2016) 12.

[9] D. Degrelle, C. Mavon, J.-E. Groetz, Nucl. Instrum. Methods Phys. Res. A 816 (2016) 47.

[10] A.S.E. Santo, F.G. Wasserman, C.C. Conti, Ann. Nucl. Energy 46 (2012) 213.

[11] R. Casanovas, J.J. Morant, M. Salvadó, Nucl. Instrum. Methods Phys. Res. A 675 (2012) 78.

[12] Y. Morera-Gómez, H.A. Cartas-Aguila, C.M. Alonso-Hernández, C. Nuñez Duartes, Nucl. Instrum. Methods Phys. Res. A 818 (2016) 51.

[13] R. Britton, A.V. Davies, Nucl. Instrum. Methods Phys. Res. A 786 (2015) 12

[14] R. Luís, J. Bento, G. Carvalhal, P. Nogueira, L. Silva, P. Teles, P. Vaz, Nucl. Instrum. Methods Phys. Res. A 623 (2010) 1014.

[15] E. García-Toraño, B. Caro, V. Peyrés, M. Mejuto, Nucl. Instrum. Methods Phys. Res. A 837 (2016) 63.

[16] J.G. Guerra, J.G. Rubiano, G. Winter, A.G. Guerra, H. Alonso, M.A. Arnedo, A. Tejera, J.M. Gil, R. Rodríguez, P. Martel, J. Environ. Radioact. 149 (2015) 8.

[17] J.G. Guerra, J.G. Rubiano, G. Winter, A.G. Guerra, H. Alonso, M.A. Arnedo, A. Tejera, P. Martel, J.P. Bolivar, Nucl. Instrum. Methods Phys. Res. A 858 (2017) 113.

[18] R. Storn, K. Price, J. Global Optim. 11 (1997) 341.

[19] F. Salvat, J.M. Fernández-Varea, J. Sempau, PENELOPE-2011: A Code System for Monte Carlo Simulation of Electronic and Photon Transport, OECD, Barcelona, Spain, 2011.

[20] T. Robič, B. Filipič, DEMO: Differential evolution for multi-objective optimization, in: Evolutionary Multi-Criterion Optimization, EMO 2005, in: Lecture Notes in Computer Science, vol. 3410, Springer, Berlin, 2005, p. 520.

[21] Model S573/S574 ISOCS/LabSOCS Validation \& Verification Manual V.4.0, Canberra Industries Inc., 2002.

[22] Preparation and Certification of IAEA Gamma Spectrometry Reference Materials RGU-1, RGTh-1 and RGK-1, IAEA Report RL148, International Atomic Energy Agency, Vienna, 1987.

[23] Genie 2000, Basic Spectroscopy Software Version 2.1., Canberra Industries Inc., 2002.

[24] A. Shakhashiro, S. Tarjan, A. Ceccatelli, G. Kis-Benedek, M. Betti, Appl. Radiat. Isot. 70 (2012) 1632.

[25] IAEA-447- Natural and artificial radionuclides in moss-soil. <http://nucleus.iaea. org/rpst/Documents/RS_IAEA-447.final.pdf>.

[26] A.R. Iurian, A. Pitois, G. Kis-Benedek, A. Migliori, R. Padilla-Alvarez, A. Ceccatelli, Appl. Radiat. Isot. 109 (2016) 61.

[27] A. Ceccatelli, R. Katona, G. Kis-Benedek, A. Pitois, Appl. Radiat. Isot. 87 (2014) 461.
[28] IAEA-448-Radium-226 in soil from oil field. <http://nucleus.iaea.org/rpst/Referen ceProducts/ReferenceMaterials/Radionuclides/RS_IAEA-448.pdf $>$.

[29] Worldwide open proficiency test: determination of naturally occurring radionuclides in phosphogypsum and water IAEA-CU-2008-03. IAEA Analytical Quality in Nuclear Applications Series No. IAEA/AQ/18 International Atomic Energy Agency, Vienna, 2010.

[30] A. Shakhashiro, U. Sansone, H. Wershofen, A. Bollhöfer, C.K. Kim, C.S. Kim, G. KisBenedek, M. Korun, M. Moune, S.H. Lee, S. Tarjan, M.S. Al-Masri, Appl. Radiat. Isot. 69 (2011) 231.

[31] Report on the Intercomparison Run for the Determination of Radionuclides in Soils IAEA-326 and IAEA-327. IAEA/AL/100. International Atomic Energy Agency, Vienna, 2001.

[32] CANMET: <https://www.nrcan.gc.ca/mining-materials/certified-reference-materia ls/certificate-price-list/8009>.

[33] DH-la: A Certified Uranium-Thorium Reference Ore, CANMET Report 81-11E, Canada Centre for Mineral and Energy Technology, Canada, 1981.

[34] Chart of the Nuclides, National Nuclear Data Center, Brookhaven National Laboratory, <http://www.nndc.bnl.gov/chart/>.

[35] G. Xhixha, M. Alberi, M. Baldoncini, K. Bode, E. Bylyku, F. Cfarku, I. Callegari, F. Hasani, S. Landsberger, F. Mantovani, E. Rodriguez, F. Shala, V. Strati, M. Xhixha Kaçeli, J. Radioanal. Nucl. Chem. 307 (2016) 1507.

[36] E. Tomarchio, S. Rizzo, Radiat. Phys. Chem. 80 (2011) 318.

[37] International Organization for Standardization, 2005. Statistical methods for use in proficiency testing by interlaboratory comparisons, in: ISO 13528 (E) Geneva, Switzerland.

[38] A. Shakhashiro, L. Mabit, Appl. Radiat. Isot. 67 (2009) 139.

[39] A. Shakhashiro, A. Trinkl, U. Sansone, Appl. Radiat. Isot. 66 (2008) 1722.

[40] I. Osvath, S. Tarjan, A. Pitois, M. Groening, D. Osborn, Appl. Radiat. Isot. 109 (2016) 90.

[41] A. Harms, M. Khanh Pham, O. Blinova, S. Tarjan, H. Nies, I. Osvath, Appl. Radiat. Isot. 126 (2017) 252.

[42] Report on the Second Almera Network Coordination Meeting and the Almera Soil Sampling Intercomparison Exercise IAEA/SIE/01. IAEA/AL/164. International Atomic Energy Agency. Seibersdorf, 2006.

[43] Worldwide Open Proficiency Test: Determination of Natural and Artificial Radionuclides in Moss-Soil and Water IAEA-CU-2009-03. IAEA Analytical Quality in Nuclear Applications Series No. IAEA/AQ/22. International Atomic Energy Agency, Vienna, 2012.

[44] ALMERA Proficiency Test: Determination of Natural and Artificial Radionuclides in Soil and Water IAEA-TEL-2011-04. IAEA Analytical Quality in Nuclear Applications Series No. IAEA/AQ/32. International Atomic Energy Agency, Vienna, 2013.

[45] Worldwide Open Proficiency Test on the Determination of Radionuclides in Spinach, Soil and Water IAEA-CU-2007-03. IAEA Analytical Quality in Nuclear Applications Series No. IAEA/AQ/8. International Atomic Energy Agency, Vienna, 2007. 